\title{
Amyloid precursor protein cooperates with c-KIT mutation/overexpression to regulate cell apoptosis in AML1-ETO-positive leukemia via the PI3K/AKT signaling pathway
}

\author{
GUOPAN YU $^{1}$, CHANGXIN YIN $^{1}$, LING JIANG $^{1}$, ZHONGXIN ZHENG $^{1}$, ZHIXIANG WANG $^{1}$, \\ CHUNLI WANG $^{1}$, HONGSHENG ZHOU ${ }^{1}$, XUEJIE JIANG ${ }^{1}$, QIFA LIU $^{1}$ and FANYI MENG ${ }^{1,2}$ \\ ${ }^{1}$ Department of Hematology, Nanfang Hospital, Southern Medical University, Guangzhou, Guangdong 510515; \\ ${ }^{2}$ Hematopathy Diagnosis and Therapy Center, Kanghua Hospital, Dongguan, Guangdong 523080, P.R. China
}

Received March 24, 2016; Accepted April 22, 2016

DOI: $10.3892 /$ or.2016.4963

\begin{abstract}
It has been reported that amyloid precursor protein (APP) promotes cell proliferation and metastasis in various types of solid cancers. In our previous study, we showed that APP is highly expressed and regulates leukemia cell migration in AML1-ETO-positive (AE) leukemia. Whether APP is involved in the regulation of AE leukemia cell proliferation or apoptosis is unclear. In the present study we focused on the correlation of APP with c-KIT mutation/ overexpression and cell proliferation and apoptosis in $\mathrm{AE}$ leukemia. APP and c-KIT expression detected by quantitative real-time (qPCR) method, and c-KIT mutations screened using PCR in bone marrow cells from 65 patients with AE leukemia before their first chemotherapy, were simultaneously assessed. Furthermore, the Kasumi-1 cell line was chosen as the cell model, and the APP gene was knocked down using siRNA technology. The correlation of cell cycle distribution and apoptosis and c-Kit expression with APP expression levels, as well as the regulation of the PI3K/AKT signaling pathway by APP were analyzed in the Kasumi-1 cell line. The results showed that peripheral white blood cell counts $(\mathrm{P}=0.008)$ and bone marrow cellularity $(\mathrm{P}=0.031)$, but not bone marrow blasts, were correlated with APP expression. Moreover, the patients with APP high expression had a significantly higher incidence of c-KIT mutations $(\mathrm{P}<0.001)$ and increased levels of c-KIT expression $(\mathrm{P}=0.001)$ and poorer disease outcome. In the Kasumi-1 cell line, as compared with the wild-type and negative control cells, cell apoptosis, both early $(\mathrm{P}<0.001)$
\end{abstract}

Correspondence to: Professor Fanyi Meng, Department of Hematology, Nanfang Hospital, Southern Medical University, 1838 North Guangzhou Avenue, Guangzhou, Guangdong 510515, P.R. China

E-mail: mengfu@medmail.com.cn

Key words: amyloid precursor protein, cell apoptosis, AML1-ETO, c-KIT, PI3K/AKT and late $(\mathrm{P}<0.001)$, was significantly increased when the APP gene was knocked down, concomitant with reduced levels of anti-apoptotic protein Bcl-2 and increased levels of caspase-3 and -9, however, no apparent change was observed in the cell cycle distribution $(\mathrm{P}>0.05)$. Moreover, the knockdown of APP markedly decreased c-KIT expression at both the transcription (as evidenced by qPCR analysis) and translation (as confirmed by CD117 assay and western blot analysis) levels, as well as p-AKT and its downstream targets including NF- $\mathrm{B}$, p53 and Bcl-2. In conclusion, APP may cooperate with c-KIT mutation/overexpression in the regulation of cell apoptosis but not proliferation in AE leukemia via the PI3K/AKT signaling pathway.

\section{Introduction}

The AML1-ETO (AE) fusion protein, which originates from the $t(8 ; 21)$ chromosomal rearrangement, is one of the most frequent translocation products found in de novo acute myeloid leukemia (AML) (1). Murine experiment data have demonstrated that AE alone is not sufficient to induce leukemia (2-4), but requires altered signal transduction pathways for leukemia progression (5), suggesting a model of AML pathogenesis in which the two groups of genetic alterations are required for the induction of the full-blown disease. c-KIT mutations are considered as one of the most important subsequent events (up to $48 \%$ ) in leukemia cases harboring $\mathrm{AE}$, and have adverse effects on the disease outcome (5-7). Furthermore, synergism between c-KIT mutation and AE in the induction of AML has been demonstrated (8-9). A recent study (10) further revealed that activated c-KIT upregulates the PI3K/AKT signaling pathway and reverts AE-induced DNA damage and apoptosis, which accounts for the increased chemo-resistance observed in $\mathrm{t}(8 ; 21)$-positive AML patients with activated c-KIT mutations. However, the reason for the high incidence of c-KIT mutations and the exact mechanisms involved in the synergism of AE with mutated-c-KIT in AE leukemia remain unclear.

Amyloid precursor protein (APP), a type I integral membrane protein, generated by the APP gene which is located 
Table I. Clinical characteristics of the AML1-ETO-positive leukemia patients.

\begin{tabular}{lllr}
\hline Characteristics & \multicolumn{1}{c}{ APP-H $(\mathrm{n}=33)$} & APP-L $(\mathrm{n}=32)$ & P-value \\
\hline Median age (range), in years & $30(5-69)$ & $28.5(4-58)$ & 0.890 \\
Gender, male/female (ratio) & $22 / 11(2.0)$ & $18 / 14(1.3)$ & 0.388 \\
WBC (x109/1) (range) & $22.3(3.1-97.6)$ & $12.4(1.7-70.3)$ & 0.008 \\
Marrow blasts, \% (range) & $38.0(12.0-94.0)$ & $33.5(12.0-93.0)$ & 0.423 \\
Bone marrow cellularity, \% (range) & $91.0(47.0-99.0)$ & $83.0(52.0-98.0)$ & 0.031 \\
c-KIT mutations/total cases & $15 / 33$ & $2 / 32$ & $<0.001$ \\
c-KIT expression level (range) & $0.00424(0.00001-0.08479)$ & $0.00057(0.00004-0.01418)$ & 0.001
\end{tabular}

APP-H, amyloid precursor protein high expression; APP-L, amyloid precursor protein low expression; WBC, white blood cells.

on 21q21.3, is implicated in synapse formation and plasticity. One of the processed APP products, $\beta$-amyloid, is directly related to the pathogenesis of neurodegenerative disorders such as Alzheimer's disease (11). APP is also ubiquitously expressed in nonneuronal tissues, and may also be involved in the growth of various cell types in both physiological and abnormal states. It has been shown that APP promotes cancer cell proliferation and metastasis and its overexpression in oral squamous cell carcinoma, pancreatic and colorectal cancer has an adverse effect on prognosis (12-15). Moreover, APP is also highly expressed in AML harboring complex karyotypes or $\mathrm{t}(8 ; 21)(16,17)$. Notably, APP plays an important role in AE leukemia and its overexpression enhances migration of Kasumi-1 cells by MMP-2 (18). In the present study, we showed that, from the results obtained from the clinical observation, APP was positively correlated with c-KIT mutations/ overexpression and had prognostic predictive value; from the data obatined from the cell model experiment, APP regulated cell apoptosis but not proliferation and was involved in the regulation of c-Kit expression and the PI3K/AKT signaling pathway, in AE leukemia. Our study indicates that APP may cooperate with c-KIT mutations/overexpression in the regulation of cell apoptosis via the PI3K/AKT signaling pathway in AE leukemia, suggesting that APP overexpression in AE leukemia may be the reason for the high incidence of c-KIT mutations and APP may be involved in the synergism of AE and c-KIT mutations to induce leukemia.

\section{Materials and methods}

Patient samples. Sixty-five bone marrow samples were obtained from AE leukemia patients admitted between February 2006 and June 2013 at Nanfang Hospital and used for the analysis of APP and c-KIT mRNA expression and c-KIT mutations. Characteristics of the patients are documented in Table I. All samples were obtained upon approval of the Nanfang Hospital, Southern Medical College of Medicine Institutional Review Boards.

Quantitative real-time polymerase chain reaction ( $q P C R)$ analysis. For each patient, a bone marrow sample was collected at diagnosis and mononuclear cells were enriched by density gradient centrifugation with Ficoll solution. Total RNA extraction and cDNA synthesization were carried out,
Table II. Sequences of the PCR primers for each gene.

\begin{tabular}{lcc}
\hline Gene & Primers & \multicolumn{1}{c}{ Sequences } \\
\hline APP & F & 5'-TGGCCCTGGAGAACTACATC-3' \\
& $\mathrm{R}$ & 5'-AATCACACGGAGGTGTGTCA-3' \\
c-KIT & $\mathrm{F}$ & 5'-CACCGAAGGAGGCACTTACAC-3' \\
& $\mathrm{R}$ & 5'-GGAATCCTGCTGCCACACA-3' \\
$\beta$-actin & $\mathrm{F}$ & 5'-CGTCTTCCCCTCCATCG-3' \\
& $\mathrm{R}$ & 5'-CTCGTTAATGTCACGCAC-3' \\
\hline
\end{tabular}

APP, amyloid precursor protein; F, forward; R, reverse.

Table III. Sequence of PCR primers for c-KIT mutation detection.

\begin{tabular}{lcc}
\hline Gene & Primers & \multicolumn{2}{c}{ Sequences } \\
\hline KIT & & \\
Exon 8 & F & 5'-CTCCCTGAAAGCAGAAAC-3' \\
& R & 5'-CAGAAAGATAACACCAAAATAG-3' \\
Exon 17 & F & 5'-GCAAAGGCATATTAGGAACTC-3' \\
& R & 5'-GTTGTAGTAATGTTCAGCATACC-3'
\end{tabular}

F, forward; R, reverse.

and PCR primer sequences for APP, c-KIT and $\beta$-actin are presented in Table II. APP and c-KIT mRNA expression as assessment by qPCR was previously described (18).

Molecular analysis. DNA from mononuclear cells, isolated from the 65 patient bone marrow samples obtained at diagnosis, was extracted using a DNA extraction kit (Qiagen) according to the manufacturer's instructions. The screening of the c-KIT (exon 8 and 17) mutations was performed by PCR and direct Sanger sequencing. PCR primers are presented in Table III. The total reaction volume of $25 \mu \mathrm{l}$ contained $2 \mu \mathrm{l}$ DNA (100 $\mathrm{ng}), 1 \mu \mathrm{l}$ of each primer (50 pmol), $12.5 \mu \mathrm{l}$ PCR mix (Takara)

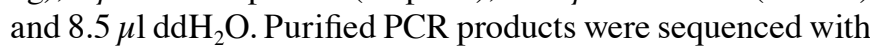


A

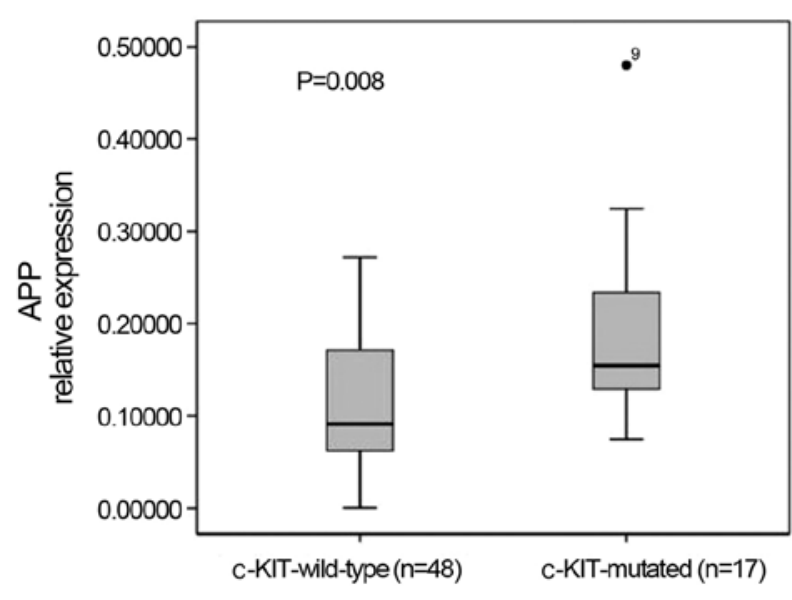

B

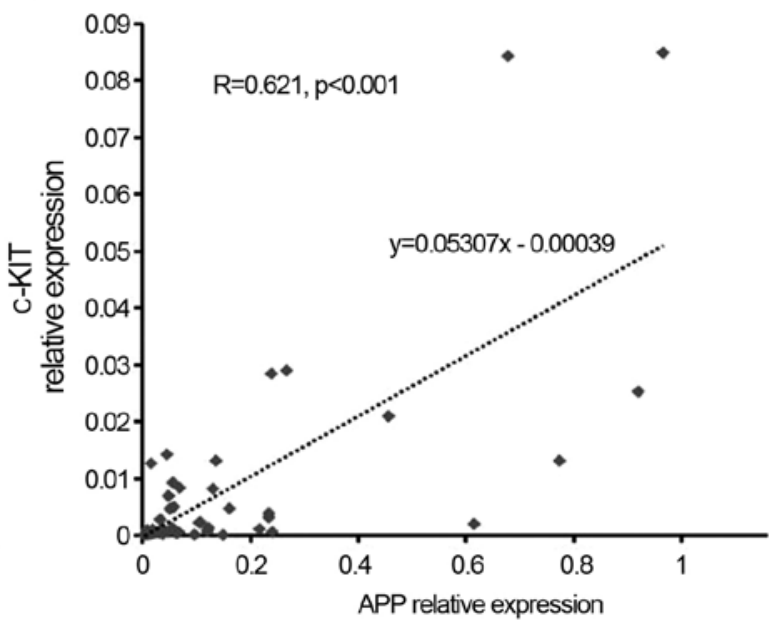

Figure 1. Amyloid precursor protein (APP) is positively correlated with c-KIT mutations/overexpression in AML1-ETO-positive leukemia patients. (A) APP was expressed significantly higher in the patients with c-KIT mutations, with the median at 0.15427 (range 0.07432-3.18640), as compared with the expression noted in the cases without c-KIT mutations, with the median at 0.09132 (range 0.00041-1.19080) $(\mathrm{P}=0.008)$. (B) Pearson rank correlation analysis showed a positive correlation of c-KIT relative expression with APP relative expression $(\mathrm{r}=0.621, \mathrm{P}<0.001)$.

Sanger sequencing. The results were analyzed with Chromas software (Technelysium Pty Ltd.).

Cell cycle distribution, apoptosis and c-KIT mutation/ expression assays in Kasumi-1 cells. To further analyze the correlation of cell proliferation and apoptosis with APP expression, the Kasumi-1 cell line, which harbors the AML1-ETO fusion gene, a c-KIT mutation (19), and has high expression of APP (17), was chosen as a cell model. According to our previous study (18), APP was silenced in the Kasumi-1 cells by lentivirus transduction, and the cells were defined as siRNA-APP-treated (siAPP) Kasumi-1 cells; in the same manner, another group of Kasumi-1 cells was transfected with scramble siRNA (TTCTCCGAACGTGTCACGT) and served as a negative control (NC). Using flow cytometric analysis, we assessed the expression of CD117, the cell cycle distribution and apoptosis in the siAPP, NC and wild-type Kasumi-1 cells. Using the PCR method, the screening of mutations and expression levels of c-KIT were assessed.

Western blot analysis. The proteins, resolved from the siAPP, NC and wild-type Kasumi-1 cells, respectively, underwent centrifugation and quantification, and were used for western blot analysis as previously described (18). The analysis of Bcl-2 (Abcam, Cambridge, MA, USA), c-Kit and p-AKT (both from Cell Signal Technology; CST), p53 and NF- $\kappa$ B (both from Abcam), caspase-3 and caspase-9 (both from CST), with their relative primary monoclonal antibodies was performed following the manufacturer's instructions, and GAPDH (Abcam) was chosen as the standard control.

Statistical analysis. SPSS 17.0 software (SPSS Inc., Chicago, IL, USA) was used for the statistical analysis. Data are expressed as the means \pm standard deviation. Statistical analysis was performed by one-way ANOVA followed by Fisher's post hoc test procedure for assessment of significance $(\mathrm{P}<0.05)$.

\section{Results}

APP is correlated with c-KIT mutations/overexpression and is indicative of poor disease outcome in patients with AE leukemia. The 65 patients were divided into an APP high expression (APP-H) group ( $n=33$, with the level of APP greater than the median level) and an APP low expression (APP-L) group ( $n=32$, with the level of APP less than the median level) according to the median value of APP relative expression levels. The results from analysis of the clinical characteristics of the patients in the APP-H and the APP-L group showed that a significantly higher peripheral white blood cell (WBC) count $\left(29.2 \pm 3.9 \times 10^{9} / 1\right.$ vs. $\left.17.9 \pm 2.9 \times 10^{9} / 1, \mathrm{P}=0.008\right)$ and bone marrow cellularity $(86.7 \pm 1.7$ vs. $80.3 \pm 2.3 \%, P=0.031)$ were observed in the APP-H patients when compared with these values in the APP-L patients, while there was no statistical difference in the bone marrow blasts. Moreover, APP was correlated with c-KIT mutations/overexpression, in that 15 out of $17 \mathrm{c}$-KIT-mutated cases belonged to the APP-H group (15/33), whereas only two mutations were observed in the APP-L group (2/32, P<0.001, Table I). Meanwhile, APP was expressed apparently higher in the c-KIT-mutated patients $(\mathrm{P}=0.008$,Fig. $1 \mathrm{~A})$ and its expression levels were positively correlated with c-KIT mRNA expression $(\mathrm{r}=0.621, \mathrm{P}<0.001$, Fig. 1B). In addition, APP overexpression indicated poor disease outcome, in that both the relapse-free survival (RFS) rate $(36.8 \pm 5.4$ vs. $72.5 \pm 7.3 \%, \mathrm{P}<0.001)$ and the overall survival $(\mathrm{OS})$ rate $(49.7 \pm 7.1$ vs. $78.0 \pm 6.5 \%, \mathrm{P}=0.027)$ were significantly lower in the APP-H group than that in the APP-L group (Fig. 2).

APP is involved in the regulation of cell apoptosis but not proliferation in Kasumi-1 cells. As APP promotes cell proliferation in some solid cancers $(12,14,15)$, we compared the cell cycle distribution of single vs. double oncogene-expressing cells during the course of ex vivo expansion. Notably, no obvious differences were observed among the siAPP, NC and wild-type cells (Fig. 3D), indicating that proliferation was not correlated 
A

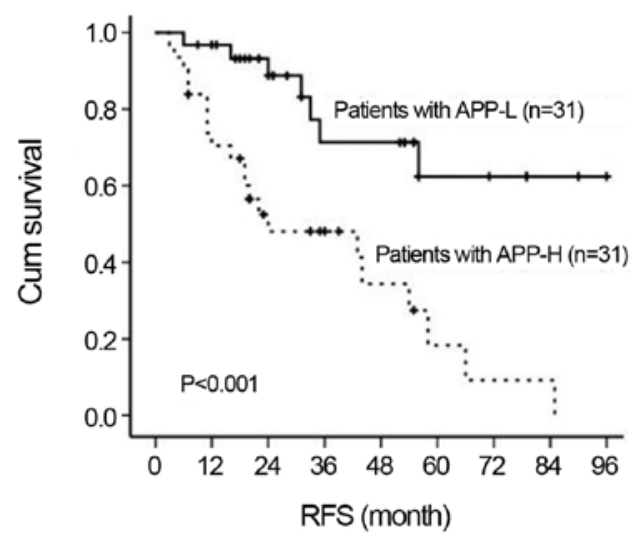

B

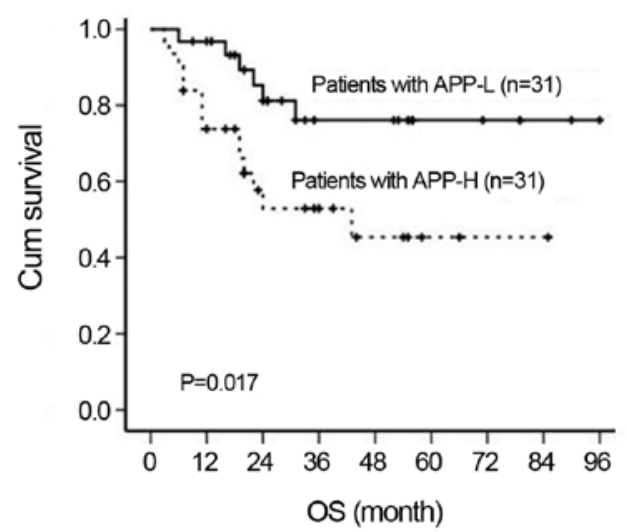

Figure 2. APP overexpression is an indicator of poor disease outcome in AML1-ETO-positive leukemia patients. Notable differences in (A) relapse-free survival (RFS) and (B) overall survival (OS) existed between patients in the APP-H and the APP-L groups. APP, amyloid precursor protein; APP-H, amyloid precursor protein high expression; APP-L, amyloid precursor protein low expression.

A
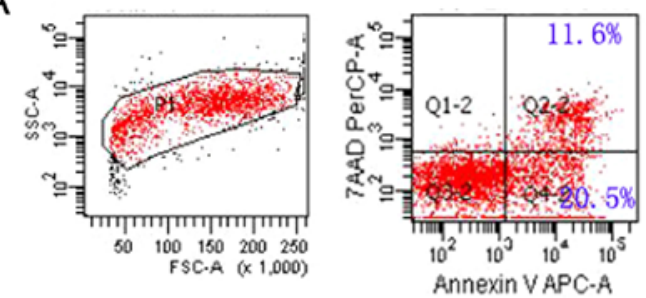

Wild

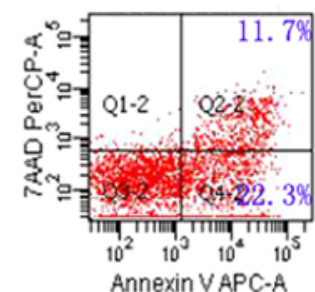

NC

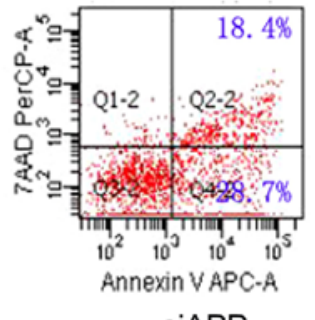

SIAPP
B

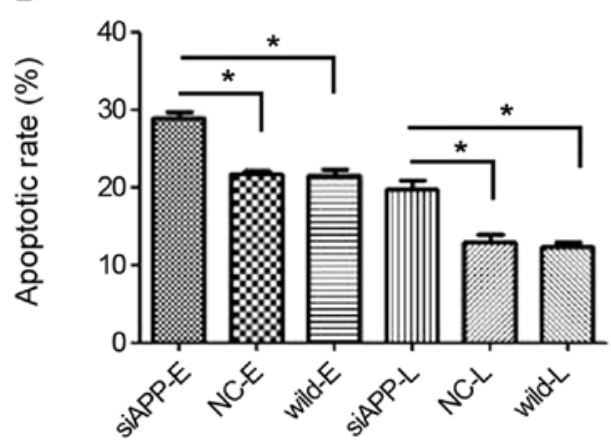

C

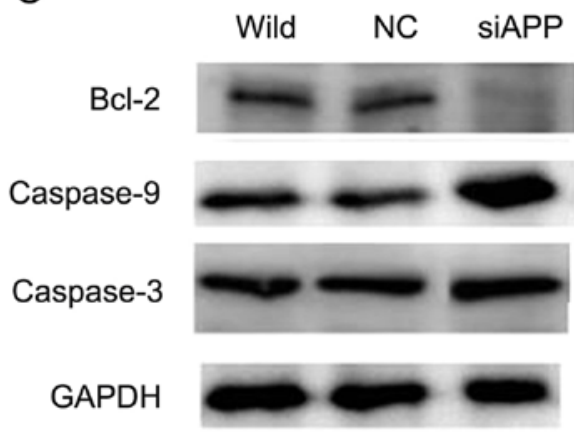

D
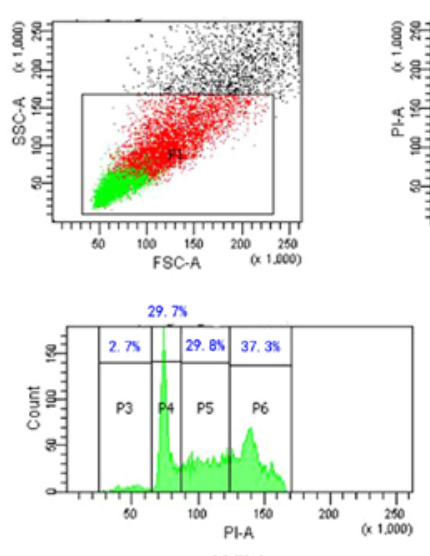

Wild
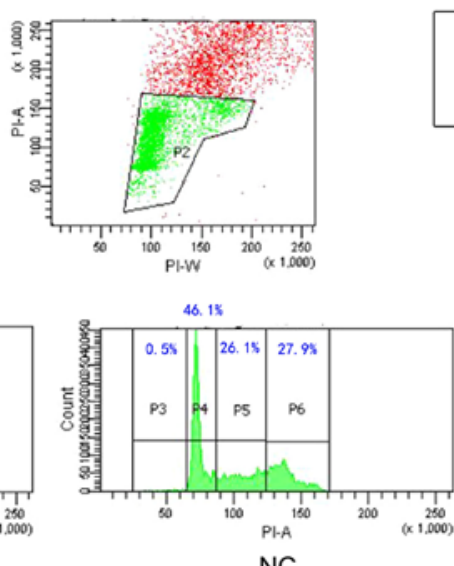

NC

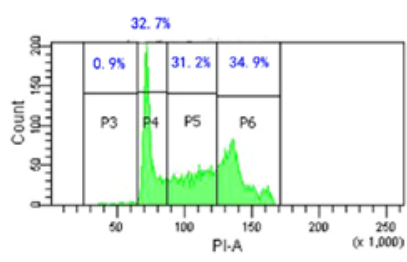

SiAPP

Figure 3. Amyloid precursor protein (APP) regulates cell apoptosis but not cell proliferation in Kasumi-1 cells. (A and B) Flow cytometric analysis showed that both the early (Q4-2) and late apoptosis (Q2-2) rates in the siRNA/App-treated (siAPP) Kasumi-1 cells increased significantly when compared with the rate in the wild-type and negative control (NC) Kasumi-1 cells (early apoptosis rate: $\mathrm{P}<0.001$; late apoptosis rate: $\mathrm{P}<0.001)$. (C) Western blot analysis showed that anti-apoptosis protein Bcl-2 decreased while caspase-3 and -9 increased markedly in the siAPP Kasumi-1 cells compared with the wild-type and NC Kasumi-1 cells. (D) No obvious difference in cell cycle distribution was observed in the wild-type, NC and siAPP Kasumi-1 cells with cell cycle analysis (P>0.05). 


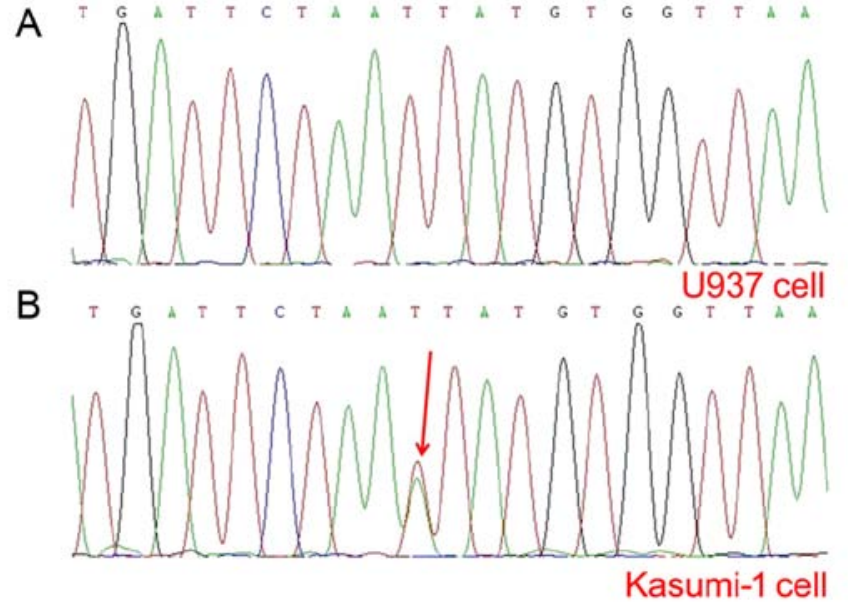

Figure 4. c-KIT mutation (N822K) exists in Kasumi-1 cells. (A) The U937 cell line without c-KIT mutations was chosen as the negative control (B) c-KIT mutation (N822K) was detected by PCR analysis in the Kasumi-1 cells, as indicated by the arrow.

with APP expression in AE leukemia. However, cell apoptosis, both early and late, as estimated by analyzing Annexin-V, increased significantly when APP was knocked down in the Kasumi-1 cells, in that the early and late apoptosis rates in the siAPP cells were $29.00 \pm 0.98$ and $19.80 \pm 1.51 \%$, respectively; when compared with $21.43 \pm 0.86$ and $12.33 \pm 0.75 \%$ in the wildtype cells and $21.67 \pm 0.78$ and $12.90 \pm 1.25 \%$ in the NC cells, respectively, there were statistical differences (early apoptosis: $\mathrm{F}=71.927, \mathrm{P}<0.001$; late apoptosis rate: $\mathrm{F}=35.239, \mathrm{P}<0.001$, respectively, Fig. 3A and $\mathrm{B}$ ). In parallel, western blotting analysis (Fig. 3C) revealed reduced levels of the anti-apoptotic protein Bcl-2 and increased levels of activated caspase-3 and caspase-9 in the siAPP cells, which also implied an increase in the basal apoptosis rate.

Knockdown of APP downregulates c-KIT expression. It is known that Kasumi-1 cells harbor c-KIT mutation (19) and mutated c-KIT upregulates c-KIT expression and decreases AE leukemia cell apoptosis (10). Our PCR assay verified the fact that a c-KIT mutation (N822K) (Fig. 4B) and c-KIT overexpression existed in the Kasumi-1 cell line. In accordance with the correlation of APP with c-KIT mutations/overexpression in our clinical observations, we further analyzed the difference in CD117 or c-KIT mRNA expression levels among the siAPP, NC and wild-type cells and found that both CD117 (by flow cytometric analysis, siAPP: $80.66 \pm 0.69 \%$, wild-type: $93.30 \pm 0.89 \%$, NC: $91.28 \pm 0.42 \%$, respectively; $\mathrm{F}=78.71, \mathrm{P}=0.006$, Fig. $5 \mathrm{~A}$ ) and $\mathrm{c}-\mathrm{KIT}$ mRNA expression levels (by qPCR analysis, siAPP: 0.05273 \pm 0.00873 , wild-type: $0.09008 \pm 0.00712$, NC: $0.08707 \pm 0.00676$, respectively; $\mathrm{F}=22.46, \mathrm{P}=0.002$, Fig. 5B) in the siAPP Kasumi-1 cells decreased significantly, as compared with those in the wild-type and NC Kasumi-1 cells. The result of western blotting analysis revealed (Fig. 5C) that c-Kit protein decreased when APP was knocked down further confirming the involvement of APP in the regulation of c-KIT expression.

siRNA-APP downregulates the PI3K/AKT signaling pathway. As the PI3K/AKT pathway, enhanced by activated c-KIT (10), is an intracellular signaling pathway which is important in the regulation of cell apoptosis in AE leukemia $(20,21)$, we evaluated the correlation of APP expression levels with the PI3K/AKT pathway using western blot analysis. The data revealed decreased levels of AKT phosphorylation concomitant
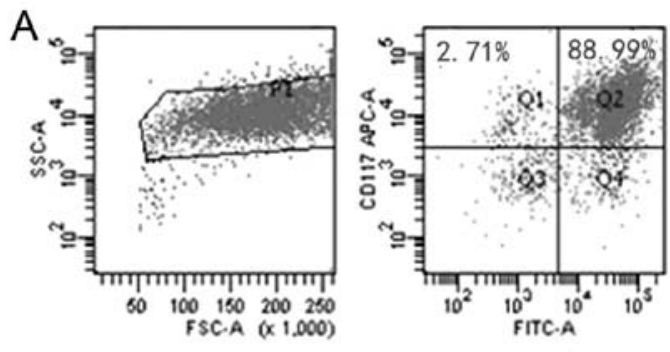

Wild

B

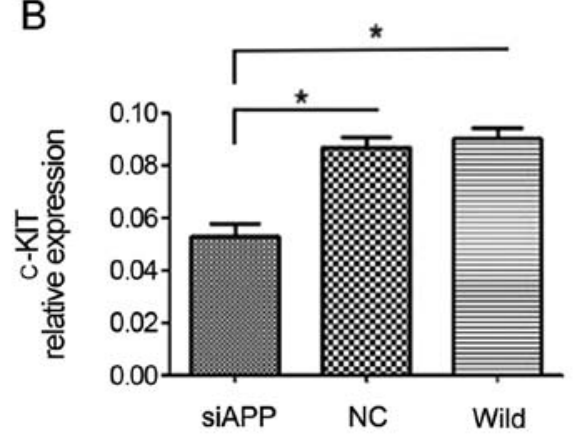

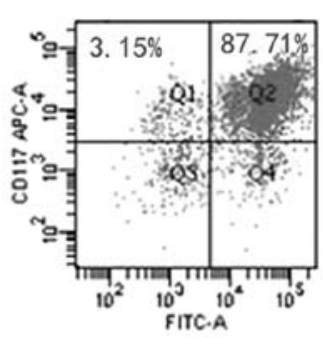

NC

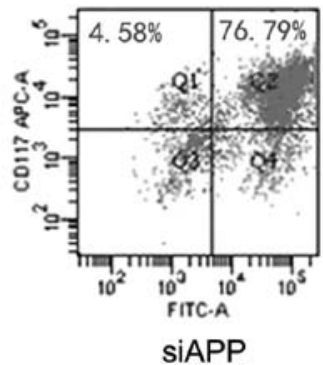

C

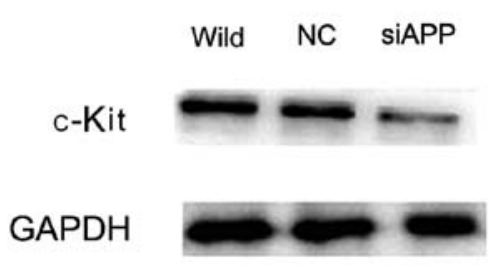

Figure 5. Knockdown of amyloid precursor protein (APP) downregulates c-KIT expression. c-KIT expression levels were observed to be significantly decreased in the siRNA/APP-treated (siAPP) Kasumi-1 cells, as compared with the levels noted in the wild-type and negative control (NC) Kasumi-1 cells, as determined by (A) the data of the CD117 expression analysis using flow cytometric analysis and (C) c-KIT mRNA expression levels as detected by qPCR method and (C) protein c-KIT expression as assessed with western blot analysis. 


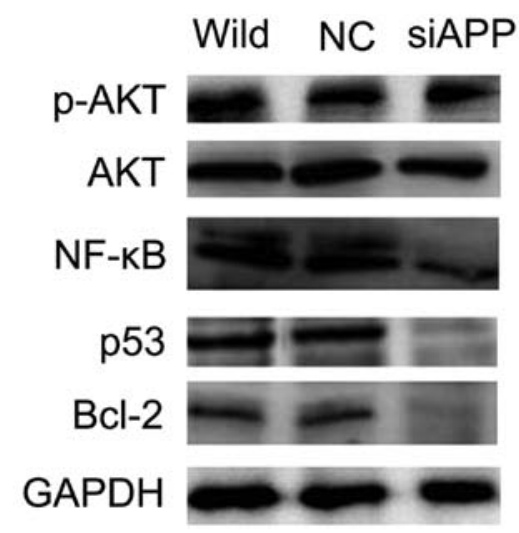

Figure 6. Knockdown of amyloid precursor protein (APP) downregulates the expression of the PI3K/AKT signaling pathway. Western blot analysis showed that the expression of p-AKT, concomitant with the downstream effector molecules of the PI3K/AKT signaling pathway including NF- $\mathrm{B}$, p53 and Bcl-2 were significantly decreased in the siRNA/App-treated (siAPP) Kasumi-1 cells.

with reduced transcription factors $\mathrm{p} 53$ and $\mathrm{NF}-\kappa \mathrm{B}$, both of which are important downstream receptors in the PI3K/AKT pathway and play a vital role in the regulation of cell apoptosis (22-24), in the siAPP Kasumi-1 cells, as compared with the levels in the NC and wild-type Kasumi-1 cells (Fig. 6), suggesting that APP mediates Kasumi-1 cell apoptosis via the PI3K/AKT pathway.

\section{Discussion}

It is known that APP promotes cancer cell proliferation and metastasis and has an adverse effect on disease outcome in various solid cancers (12-15). The effect of APP on migration and prognosis in AE leukemia was reported in our previous study (18). In this study, we showed that APP decreased cell apoptosis but did not promote cell proliferation, in accordance with the finding that APP may lead to leukemia progression due to abnormal apoptosis (16); knockdown of APP increased cell apoptosis but did not significantly affect cell proliferation in AE leukemia. In parallel, from the clinical data, we observed significantly a higher peripheral WBC count and bone marrow cellularity in the APP-H patients than these parameters in the APP-L cases, while there was no apparent difference in the bone marrow blasts between the two groups. We also determined that APP is correlated with c-KIT mutations/overexpression in $\mathrm{AE}$ leukemia patients. In an in vitro study, we further demonstrated the involvement of APP in the regulation of c-KIT expression and the PI3K/AKT signaling pathway, which play important roles in cell apoptosis regulation.

Notably, our clinical data demonstrated that c-KIT mutations were frequent in the APP-H patients and the expression levels of APP and c-KIT were positively correlated at the transcription levels (as evidenced by qPCR analysis). This suggests that APP is closely correlated with c-KIT mutation/ overexpression. The correlation of APP with c-KIT expression was further confirmed at both the transcription (as evidenced by qPCR analysis) and translation (as confirmed by CD117 assay and western blot analysis) levels in the Kasumi-1 cell experiment. c-KIT mutations which are considered as one of the most important subsequent events and that are highly expressed (up to 48\%), cooperate with full length AML1-ETO to induce leukemia, and adversely affect the disease outcome, in AE leukemia. Since the APP gene is located on 21q21.3 and expresses highly in $t(8 ; 21)$, the correlation of APP with c-KIT mutations in our data may explain the high incidence of c-KIT mutations in this subtype of leukemia and indicate the involvement of APP in the progression of AE leukemia. Furthermore, activating c-KIT mutations upregulate c-KIT expression and reverse AML1-ETO-induced DNA damage and apoptosis. Based on these data, we report that APP may cooperate with c-KIT mutation/overexpression in the regulation of cell apoptosis in AE leukemia cells.

The PI3K/AKT signaling pathway is of central importance in AE leukemia and plays an important role in processes critical for leukemia progression $(20,21)$. AKT is a major downstream effector molecule of the PI3K/AKT pathway (25) and increased AKT phosphorylation implies activation of the PI3K pathway (26). AKT plays a central role in apoptosis inhibition through its regulatory effects on various downstream targets such as anti-apoptotic Bcl-2 (27) and activated caspase- 3 and -9 and transcription factors $N F-\kappa B$ and p53 (22-24). In the present study, we silenced the APP gene and found that $\mathrm{p}-\mathrm{AKT}$ and its downstream targets Bcl-2, $\mathrm{NF}-\kappa \mathrm{B}$ and $\mathrm{p} 53$ were significantly reduced while caspase-3 and caspase-9 were increased, suggesting that APP regulates cell apoptosis via the PI3K/AKT signaling pathway. Moreover, activating c-KIT mutations upregulatd the PI3K/ AKT pathway and the PI3K inhibitor increased cell apoptosis in AE leukemia. These results further support the cooperation of APP with c-KIT mutation/overexpression in the regulation of cell apoptosis via the PI3K/AKT pathway in AE leukemia.

In conclusion, APP regulates cell apoptosis but not cell proliferation in AE leukemia. The regulatory mechanism may involve the synergism of APP and c-KIT mutation/overexpression to decrease cell apoptosis via the PI3K/AKT pathway. Its exact mechanisms require further in-depth study. Moreover, our findings suggest that APP may be a new biomarker for targeted therapy in AE leukemia.

\section{Acknowledgements}

This study was funded by the National Natural Science Foundation of China (no. 81500138), the Natural Science Foundation of Guangdong Province, China (no. 2014A030313270), the Medical Research Foundation of Guangdong Province, China (no. B2014250), the Science and Technology Program of Guangzhou, China (no. 2013J4100109), the Ph.D. Programs Foundation of the Ministry of Education of China (no. 20124433110001) and the National High-Tech R\&D Program (863 Program) China (no. 2012AA02A505).

\section{References}

1. Rowley JD: Identificaton of a translocation with quinacrine fluorescence in a patient with acute leukemia. Ann Genet 16: 109-112, 1973.

2. Yergeau DA, Hetherington CJ, Wang Q, Zhang P, Sharpe AH, Binder M, Marín-Padilla M, Tenen DG, Speck NA and Zhang DE: Embryonic lethality and impairment of haematopoiesis in mice heterozygous for an AMLI-ETO fusion gene. Nat Genet 15: 303-306, 1997. 
3. Higuchi M, O'Brien D, Kumaravelu P, Lenny N, Yeoh EJ and Downing JR: Expression of a conditional AML1-ETO oncogene bypasses embryonic lethality and establishes a murine model of human $\mathrm{t}(8 ; 21)$ acute myeloid leukemia. Cancer Cell 1: 63-74, 2002.

4. Rhoades KL, Hetherington CJ, Harakawa N, Yergeau DA, Zhou L, Liu LQ, Little MT, Tenen DG, Zhang DE and Zhang DE: Analysis of the role of AML1-ETO in leukemogenesis, using an inducible transgenic mouse model. Blood 96: 2108-2115, 2000.

5. Jiao B, Wu CF, Liang Y, Chen HM, Xiong SM, Chen B, Shi JY Wang YY, Wang JH, Chen Y, et al: AML1-ETO9a is correlated with $C$-KIT overexpression/mutations and indicates poor disease outcome in $\mathrm{t}(8 ; 21)$ acute myeloid leukemia-M2. Leukemia 23 1598-1604, 2009.

6. Paschka P, Marcucci G, Ruppert AS, Mrózek K, Chen H, Kittles RA, Vukosavljevic T, Perrotti D, Vardiman JW, Carroll AJ, et al; Cancer and Leukemia Group B: Adverse prognostic significance of $K I T$ mutations in adult acute myeloid leukemia with inv(16) and t(8;21): A Cancer and Leukemia Group B Study. J Clin Oncol 24: 3904-3911, 2006.

7. Schnittger S, Kohl TM, Haferlach T, Kern W, Hiddemann W, Spiekermann K and Schoch C: KIT-D816 mutations in AML1-ETO-positive AML are associated with impaired event-free and overall survival. Blood 107: 1791-1799, 2006.

8. Wang YY, Zhao LJ, Wu CF, Liu P, Shi L, Liang Y, Xiong SM, Mi JQ, Chen Z, Ren R, et al: C-KIT mutation cooperates with full-length AML1-ETO to induce acute myeloid leukemia in mice. Proc Natl Acad Sci USA 108: 2450-2455, 2011.

9. Nick HJ, Kim HG, Chang CW, Harris KW, Reddy V and Klug CA: Distinct classes of c-Kit-activating mutations differ in their ability to promote RUNX1-ETO-associated acute myeloid leukemia. Blood 119: 1522-1531, 2012.

10. Wichmann C, Quagliano-Lo Coco I, YildizÖ,Chen-Wichmann L, Weber H, Syzonenko T, Döring C, Brendel C, Ponnusamy K, Kinner A, et al: Activating c-KIT mutations confer oncogenic cooperativity and rescue RUNX1/ETO-induced DNA damage and apoptosis in human primary $\mathrm{CD} 34^{+}$hematopoietic progenitors. Leukemia 29: 279-289, 2015.

11. Zhang MY, Zheng CY, Zou MM, Zhu JW, Zhang Y, Wang J, Liu CF, Li QF, Xiao ZC, Li S, et al: Lamotrigine attenuates deficits in synaptic plasticity and accumulation of amyloid plaques in APP/PS1 transgenic mice. Neurobiol Aging 35: 2713-2725, 2014.

12. Hansel DE, Rahman A, Wehner S, Herzog V, Yeo CJ and Maitra A: Increased expression and processing of the Alzheimer amyloid precursor protein in pancreatic cancer may influence cellular proliferation. Cancer Res 63: 7032-7037, 2003.

13. Ko SY, Lin SC, Chang KW, Wong YK, Liu CJ, Chi CW and Liu TY: Increased expression of amyloid precursor protein in oral squamous cell carcinoma. Int J Cancer 111: 727-732, 2004.

14. Krause K, Karger S, Sheu SY, Aigner T, Kursawe R, Gimm O, Schmid KW, Dralle H and Fuhrer D: Evidence for a role of the amyloid precursor protein in thyroid carcinogenesis. J Endocrinol 198: 291-299, 2008.
15. Takayama K, Tsutsumi S, Suzuki T, Horie-Inoue K, Ikeda K, Kaneshiro K, Fujimura T, Kumagai J, Urano T, Sakaki Y, et al: Amyloid precursor protein is a primary androgen target gene that promotes prostate cancer growth. Cancer Res 69: 137-142, 2009.

16. Baldus CD, Liyanarachchi S, Mrózek K, Auer H, Tanner SM, Guimond M, Ruppert AS, Mohamed N, Davuluri RV, Caligiuri MA, et al: Acute myeloid leukemia with complex karyotypes and abnormal chromosome 21: Amplification discloses overexpression of $A P P, E T S 2$, and $E R G$ genes. Proc Natl Acad Sci USA 101: 3915-3920, 2004.

17. Wang W, Meng FY, Huang ZF, Huang M and Liu LX: Expression and role of amyloid precrusor protein gene in acute myeloid leukemia. Chin J Hematol 31: 309-314, 2010 (In Chinese).

18. Jiang L, Yu G, Meng W, Wang Z, Meng F and Ma W: Overexpression of amyloid precursor protein in acute myeloid leukemia enhances extramedullary infiltration by MMP-2. Tumour Biol 34: 629-636, 2013.

19. Larizza L, Magnani I and Beghini A: The Kasumi-1 cell line: A $t(8 ; 21)$-kit mutant model for acute myeloid leukemia. Leuk Lymphoma 46: 247-255, 2005.

20. Pulikkan JA, Madera D, Xue L, Bradley P, Landrette SF, Kuo YH, Abbas S, Zhu LJ, Valk P and Castilla LH: Thrombopoietin/MPL participates in initiating and maintaining RUNX1-ETO acute myeloid leukemia via PI3K/AKT signaling. Blood 120: 868-879, 2012.

21. Kumar A, Fernandez-Capetillo O and Carrera AC: Nuclear phosphoinositide 3-kinase $\beta$ controls double-strand break DNA repair. Proc Natl Acad Sci USA 107: 7491-7496, 2010.

22. Sheng S, Qiao M and Pardee AB: Metastasis and AKT activation. J Cell Physiol 218: 451-454, 2009.

23. Wang L, Zhao WL, Yan JS, Liu P, Sun HP, Zhou GB, Weng ZY, Wu WL, Weng XQ, Sun XJ, et al: Eriocalyxin B induces apoptosis of $\mathrm{t}(8 ; 21)$ leukemia cells through $\mathrm{NF}-\kappa \mathrm{B}$ and MAPK signaling pathways and triggers degradation of AML1-ETO oncoprotein in a caspase-3-dependent manner. Cell Death Differ 14: 306-317, 2007.

24. Krejci O, Wunderlich M, Geiger H, Chou FS, Schleimer D, Jansen M, Andreassen PR and Mulloy JC: p53 signaling in response to increased DNA damage sensitizes AML1-ETO cells to stress-induced death. Blood 111: 2190-2199, 2008

25. McCubrey JA, Steelman LS, Chappell WH, Abrams SL, Montalto G, Cervello M, Nicoletti F, Fagone P, Malaponte G, Mazzarino MC, et al: Mutations and deregulation of Ras/Raf/MEK/ERK and PI3K/PTEN/Akt/mTOR cascades which alter therapy response. Oncotarget 3: 954-987, 2012.

26. Hart JR and Vogt PK: Phosphorylation of AKT: A mutational analysis. Oncotarget 2: 467-476, 2011.

27. Datta SR, Dudek H, Tao X, Masters S, Fu H, Gotoh Y and Greenberg ME: Akt phosphorylation of BAD couples survival signals to the cell-intrinsic death machinery. Cell 91: 231-241, 1997. 